\title{
Audiology
}

\section{Hearing loss in children with congenital cytomegalovirus infection: an 11-year retrospective study based on laboratory database of a tertiary paediatric hospital}

\author{
Ipoacusia e infezione congenita da citomegalovirus: \\ i risultati di uno studio retrospettivo di 11 anni basato sui dati di laboratorio
}

S. PALMA ${ }^{1}$, M.F. ROVERSI ${ }^{2}$, M. BETTINI ${ }^{3}$, S. MAZZONI², P. PIETROSEMOLI ${ }^{4}$, L. LUCACCIONI², A. BERARDI ${ }^{2}$, E. GENOVESE ${ }^{5}$

${ }^{1}$ Audiology, Primary Care Unit, Modena, Italy; ${ }^{2}$ Neonatal Intensive Care Unit, Department of Medical and Surgical Sciences of the Mother, Children and Adults, University of Modena and Reggio Emilia, Italy; ${ }^{3}$ Head and Neck

Department, University of Modena and Reggio Emilia, Italy; ${ }^{4}$ Microbiology and Virology Department, University Medical Hospital, Modena; ${ }^{5}$ Audiology, Department of Diagnostic, Clinical and Public Health University of Modena and Reggio Emilia, Italy

\begin{abstract}
SUMMARY
Congenital cytomegalovirus infection is considered the main cause of infantile non-genetic neurosensory hearing loss. Although this correlation was described more than 50 years ago, the natural history of internal ear involvement has not yet been fully defined. Hearing loss is the most frequent sequela and is seen in a variable percentage up to $30 \%$; the hearing threshold is characterised by fluctuations or progressive deterioration. The purpose of this study was to evaluate the prevalence of hearing loss in cases of congenital CMV infection from Modena county, starting from the database of the microbiology and virology reference laboratory. All children undergoing urine testing for suspected CMV infection or viral DNA testing on Guthrie Card in the period between January 2004 and December 2014 were enrolled in the study. Family paediatricians were contacted and asked about clinical information on the possible presence at birth or subsequent occurrence of hearing loss, excluding cases where this was not possible. The results showed an annual prevalence of congenital cytomegalovirus infection among suspected cases that was stable over time despite the progressive increase in subjects tested. The prevalence of hearing loss was in line with the literature, whereas in long-term follow-up cases of moderate, medium-to-severe hearing loss with late onset were not detected. The introduction of newborn hearing screening in the county has allowed early diagnosis of hearing loss at birth as non-TEOAE-born births underwent a urine virus test. Moreover, despite all the limitations of the study, we can conclude that European epidemiological studies are needed to better define the relationship between congenital CMV infection and internal ear disease as the impact of environmental and genetic factors is still not entirely clarified.
\end{abstract}

KEY WORDS: Cytomegalovirus • Congenital infection • Hearing loss • Newborn screening • Late sequelae

\section{RIASSUNTO}

Il citomegalovirus è la più comune causa di infezione congenita nei paesi industrializzati, con una prevalenza stimata intorno allo 0.3-2\% dei nati vivi. Di questi, il 10-15\% presenta sequele tardive tra cui deficit visivi, uditivi, ritardo mentale. La infezione congenita da citomegalovirus, ad oggi, è ancora ritenuta la principale causa di ipoacusia neurosensoriale infantile su base non genetica. Sebbene tale correlazione sia stata descritta più di 50 anni fa, la storia naturale del coinvolgimento dell'orecchio interno non è stata ancora completamente definita. La ipoacusia neurosensoriale è la sequela più frequente ed in una percentuale variabile, a seconda delle casistiche fino al 30\%, la soglia è caratterizzata da fluttuazioni o deterioramento progressivo. Lo scopo di questo studio è stato quello di valutare la prevalenza della ipoacusia nei casi di infezione congenita da CMV della provincia di Modena, partendo dal data base del laboratorio di Microbiologia e Virologia, centro di riferimento per la intera provincia. Inoltre, ci si è proposti di valutare la entità della ipoacusia come sequela tardiva. Sono stati arruolati tutti i bambini sottoposti ad esame delle urine per sospetta infezione da CMV o mediante ricerca del DNA virale su Guthrie Card, nel periodo compreso tra gennaio 2004 e dicembre 2014. Mediante il contributo dei pediatri di famiglia e del servizio di Audiologia di Modena sono state accolte le informazioni cliniche sulla eventuale presenza alla nascita o insorgenza successiva di ipoacusia, escludendo dallo studio i casi in cui ciò non è stato possibile. I risultati hanno dimostrato una prevalenza annuale di infezione congenita da citomegalovirus stabile nel tempo nonostante l'aumento progressivo dei nati sottoposti al test. La prevalenza della ipoacusia nei casi di infezione congenita è in linea con la letteratura mentre non sono emersi, nel lungo periodo, casi con ipoacusia media/severa bilaterale ad insorgenza tardiva. La introduzione dello screening audiologico neonatale nella nostra regione (2012) ha permesso una diagnosi precoce della ipoacusia in quanto i nati con esito fail alle TEOAE venivano sottoposti anche al test per la ricerca del virus nelle urine. Pur con tutti i limiti di uno studio basato su revisione di casistica, possiamo concludere che permane la necessità di studi epidemiologici europei che consentano di definire meglio la relazione tra infezione congenita da CMV e patologia dell'orecchio interno in quanto l'impatto dei fattori ambientali e genetici non è ancora del tutto chiarito. La sinergia tra screening audiologico neonatale ed esecuzione del test per la ricerca del virus nelle urine si è dimostrata molto proficua.

PAROLE CHIAVE: Citomegalovirus $\bullet$ Infezione congenita $\bullet$ Ipoacusia $\bullet$ Screening neonatale $\bullet$ Sorveglianza audiologica 


\section{Introduction}

Congenital cytomegalovirus (cCMV) infection is currently estimated to be the main cause of non-inherited sensorineural hearing loss ${ }^{12}$. Considered the most common congenital infection in humans, cCMV has a prevalence in the hearing-impaired children population between $2 \%$ and $18 \%{ }^{3-5}$. The virus can be transmitted to the foetus through placental blood, contact with infected vaginal secretions during delivery, breast milk, or blood transfusions after birth. The risk of transmission to the foetus is $30-35 \%$ and $1.1-1.7 \%$ for primary or non-primary maternal infection, respectively ${ }^{6}$.

Although the association between cCMV and hearing loss was first noted 50-60 years ago, the natural history of the inner ear involvement is still unclear ${ }^{7}$. Even if $85-90 \%$ of cCMV are asymptomatic at birth, $10-15 \%$ of these infants may develop hearing, visual, or neurodevelopmental impairment ${ }^{28}$. Moreover, vestibular involvement, often underestimated, may contribute to delayed motor skill acquisition in these children ${ }^{9}{ }^{10}$. In view of the fact that most newborns are asymptomatic at birth and that there are no specific screening protocols to detect infection, the actual impact of cCMV is still not completely known. Sensorineural hearing loss is the most common sequela, affecting from 33 to $65 \%$ of symptomatic newborns and from 7 to $15 \%$ of asymptomatic ones ${ }^{11}{ }^{12}$, presenting in $30 \%$ of the cases, with fluctuating auditory thresholds, characterised by deterioration or improvement over time ${ }^{111-13}$.

As no effective prenatal therapy or vaccine exist, and since most patients with cCMV recover spontaneously, no universal screening program for cCMV has yet been implemented, although its value is an increasingly debated issue ${ }^{14}$. When urine and saliva cultures obtained within the first two weeks of life are positive for CCMV, clinicians carry out complete clinical and biochemical evaluation to identify whether the infection is symptomatic or asymptomatic. The outcome of these tests affects treatment decisions, as current guidelines recommend to treat only symptomatic infants with antiviral therapy during their first 30 days of life in the presence of central nervous system disorders or in cases of focal or severe organ diseases ${ }^{15}$.

\section{Materials and methods}

Data were retrospectively collected from the laboratory database of the University Medical Hospital of Modena, the reference centre for diagnosis of viral infections for the entire county. All urinary CMV tests carried out between January 2004 (the starting point was linked to the introduction of new hospital software) and December 2014 were reviewed. As a first step, all children (0-12 years) with confirmed CMV infection were enrolled in the study. Diagnosis of CMV infection was carried out by testing urine samples using the shell vial assay (SVA). Cases of cCMV infection were defined as any newborn $\leq 14$ days of age with a positive CMV urine test or with a positive polymerase chain reaction (PCR)-CMV test confirmed on Guthrie cards. The main reasons for performing a cCMV test were: incidental finding of maternal CMV during pregnancy, abnormal prenatal cerebral ultrasound, preterm delivery, microcephaly (head circumference $<3^{\circ}$ percentile), persistent jaundice, thrombocytopenia, neutropenia. Family paediatricians were contacted and asked if their patients experienced hearing loss, and additional information regarding hearing loss was obtained from the records of the ENT/Audiology and Paediatric Departments. A new audiological evaluation was prescribed only in cases of doubt.

Since January 2012, neonates born in Modena county routinely undergo hearing testings in accordance with the screening program implemented in the Emilia Romagna region ${ }^{16}$ (a two stage Transitory Evoked Otoacoustic Emission-TEOAE protocol, carried out in accordance with the recommendations of the American Academy of Pediatrics).

Before 2012 the Auditory Brainstem Response (ABR) test was carried out only at the time of diagnosis of cCMV. Starting from 2012, in accordance with Italian paediatric guidelines ${ }^{17}$, children with cCMV infection routinely undergo ABR as part of a long-term audiological program for cCMV infected patients, which foresees assessments at 1-3 and 6 months and annual assessments up to the 6-year age for neonates with normal hearing.

The severity of sensorineural hearing loss was defined as follows: normal hearing (0-15 db), slight (16-25 db), mild ( $\geq 26$ to $<40 \mathrm{~dB}$ ); moderate ( $\geq 41$ to $<55 \mathrm{~dB}$ ), moderatesevere ( $\geq 56$ to $<70 \mathrm{~dB}$ ), severe $(\geq 71$ to $<90 \mathrm{~dB}$ ) and profound $(>90 \mathrm{~dB})$.

Demographic data were obtained from the Regional Health Agency. This study was approved by the Ethics Committee of Modena county (n. 166/14), informed consent was obtained through the family's paediatricians.

\section{Results}

Urinary CMV testing was carried out in 2966 children (3.9\% of total live births) between 2004 and 2014, 1954 (65\%) of whom were younger than 14 days (Fig. 1). Table I shows the prevalence of children tested positive or negative for cCMV in the county. CMV infection was confirmed in 339 children and information on hearing loss was available in 250 (73.8\%): 45/250 were cCMV, while 
Table. I. Number of newborns per year during the study period and number of children tested for suspected cCMV (age $<14$ days of life). The prevalence calculated on our population are reported in brackets.

\begin{tabular}{|c|c|c|c|c|c|}
\hline Year & Total newborns & $\begin{array}{l}\text { Children tested for } \\
\text { suspected cCMV } \\
\text { (prevalence \%) }\end{array}$ & $\begin{array}{l}\text { Children resulted } \\
\text { negative for cCMV } \\
\text { (prevalence \%) }\end{array}$ & $\begin{array}{l}\text { Children resulted } \\
\text { positive for cCMV } \\
\text { (prevalence \%)* }\end{array}$ & $\begin{array}{l}\text { Prevalence of cCMV } \\
\text { among tested population }\end{array}$ \\
\hline 2004 & 6553 & $\begin{array}{c}80 \\
(1.2 \%)\end{array}$ & $\begin{array}{c}72 \\
(1 \%)\end{array}$ & $\begin{array}{c}8[5] \\
(0.1 \%)\end{array}$ & $10 \%$ \\
\hline 2005 & 6770 & $\begin{array}{c}163 \\
(2.4 \%)\end{array}$ & $\begin{array}{c}157 \\
(2.3 \%)\end{array}$ & $\begin{array}{c}6[5] \\
(0.08 \%)\end{array}$ & $3.7 \%$ \\
\hline 2006 & 6703 & $\begin{array}{c}162 \\
(2.4 \%)\end{array}$ & $\begin{array}{c}158 \\
(2.3 \%)\end{array}$ & $\begin{array}{c}4 \\
(0,04 \%)\end{array}$ & $2.5 \%$ \\
\hline 2007 & 6857 & $\begin{array}{c}132 \\
(1.9 \%)\end{array}$ & $\begin{array}{c}128 \\
(1.8 \%)\end{array}$ & $\begin{array}{c}4[3] \\
(0.05 \%)\end{array}$ & $3 \%$ \\
\hline 2008 & 7201 & $\begin{array}{c}121 \\
(1.6 \%)\end{array}$ & $\begin{array}{c}118 \\
(1.6 \%)\end{array}$ & $\begin{array}{c}3 \\
(0,03 \%)\end{array}$ & $2.5 \%$ \\
\hline 2009 & 7151 & $\begin{array}{c}151 \\
(2.2 \%)\end{array}$ & $\begin{array}{l}145 \\
(2 \%)\end{array}$ & $\begin{array}{c}6[5] \\
(0.08 \%)\end{array}$ & $4 \%$ \\
\hline 2010 & 7116 & $\begin{array}{c}189 \\
(2.6 \%)\end{array}$ & $\begin{array}{c}184 \\
(2.5 \%)\end{array}$ & $\begin{array}{c}5[4] \\
(0.07 \%)\end{array}$ & $2.64 \%$ \\
\hline 2011 & 6949 & $\begin{array}{c}224 \\
(3.2 \%)\end{array}$ & $\begin{array}{c}217 \\
(3.1 \%)\end{array}$ & $\begin{array}{c}7[6] \\
(0.1 \%)\end{array}$ & $3.1 \%$ \\
\hline 2012 & 6703 & $\begin{array}{c}185 \\
(2.7 \%)\end{array}$ & 185 (2.7\%) & 0 & - \\
\hline 2013 & 6311 & $\begin{array}{c}247 \\
(3.9 \%)\end{array}$ & $\begin{array}{l}240 \\
(4 \%)\end{array}$ & $\begin{array}{c}7[5] \\
(0.1 \%)\end{array}$ & $2.8 \%$ \\
\hline 2014 & 6040 & $\begin{array}{c}300 \\
(4.9 \%)\end{array}$ & $\begin{array}{l}295 \\
(5 \%)\end{array}$ & $\begin{array}{c}5 \\
(0,08 \%)\end{array}$ & $1.66 \%$ \\
\hline Tot & 74354 & $\begin{array}{c}1954 \\
(2.8 \%)\end{array}$ & $\begin{array}{c}1899 \\
(2.5 \%)\end{array}$ & $\begin{array}{l}55[45] \\
(0.07 \%)\end{array}$ & $2.8 \%$ \\
\hline
\end{tabular}

*: The number of newborns with information about hearing impairment are reported in squared brackets.

205/250 were acquired (Fig. 2). Figure 2 also details the rates of acquired and congenital infections according to the availability of hearing loss information. All these chil-

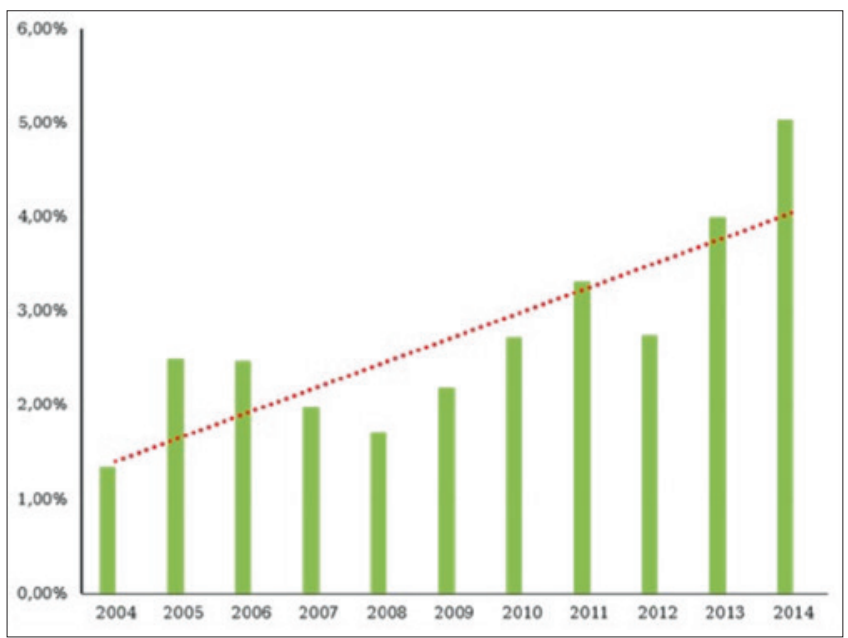

Fig. 1. Number of children screened for CMV compared to the number of newborns from 2004 to 2014. dren had at least 2 years of follow-up, and $51 \%$ had at least 8 years.

A few children $(n=6 / 250-13 \%)$ with cCMV infection had confirmed hearing impairment. Among these, 2 were diagnosed after 2012 through the neonatal hearing screening program, and were positive by TEOAE. The number of children presenting with hearing loss, the severity of disease and side of hearing impairment are shown in Table II. The prevalence of symptomatic cCMV after the introduction of newborn hearing screening (2/10) was $20 \%$, while the proportion of symptomatic $\mathrm{cCmv}$ with hearing loss before the screening was $11 \%$. Among the 205 children $(82 \%)$ with acquired CMV, 6 (2.9\%) had moderate to severe hearing impairment: in one case the Guthrie card excluded cCMV and 2 cases were associated with syndromes. The remaining 3 cases could be attributed to delayed diagnosis of cCMV (Table II). All the 6 cases with acquired CMV were born before the implementation of the newborn hearing screening.

Although the total number of samples analysed increased over the years (from 1.2\% in 2004 to $4.9 \%$ in 2014), and 


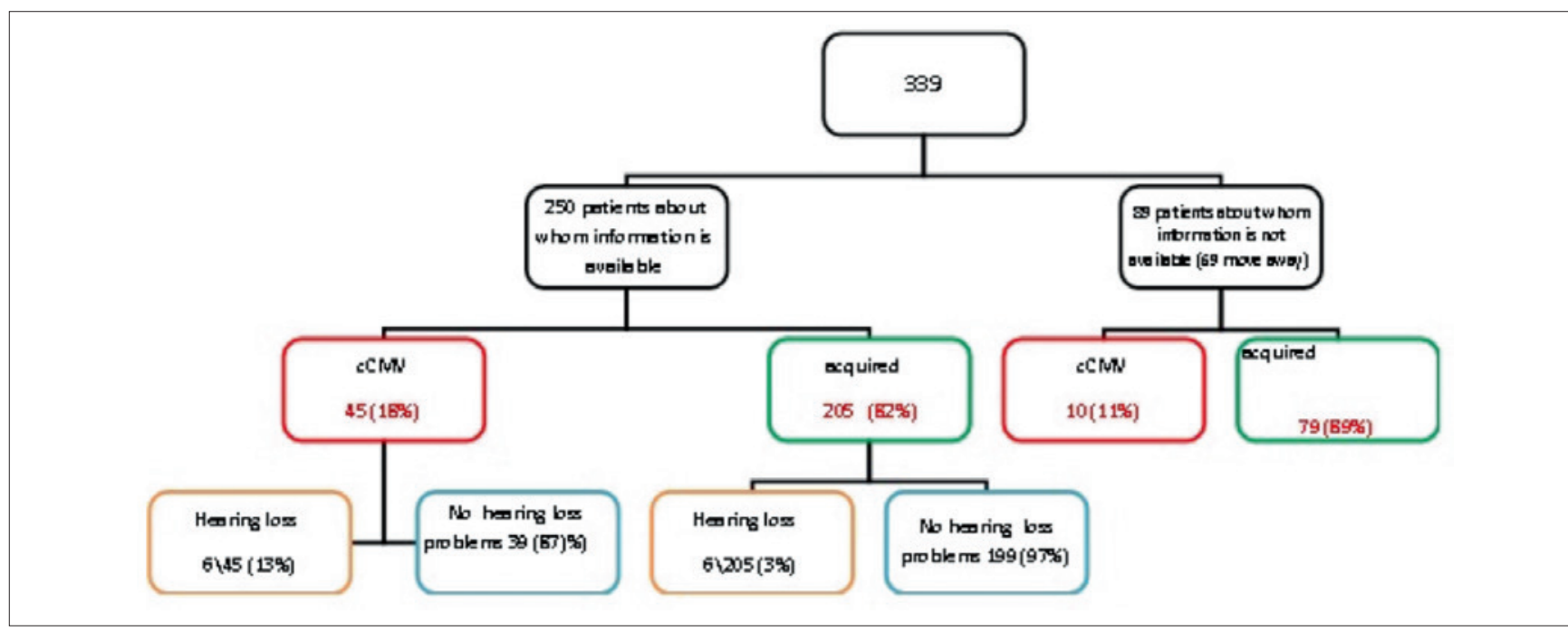

Fig. 2. Positive CMV testing.

in particular due to the introduction of the newborn hearing screening test, the prevalence of cCMV among tested children reduced from $10 \%$ to $1.6 \%$. Figure 3 shows the number of cCMV cases detected per year.

\section{Discussion}

This retrospective study is based on the laboratory database of a tertiary university hospital, which is the reference center for the entire country.

We found that the number of tested infants increased almost four-fold during the study period, demonstrating the efforts of clinicians in identification of asymptomatic infants at least among the population at high risk (i.e. preterm infants, intrauterine growth retarded infants).

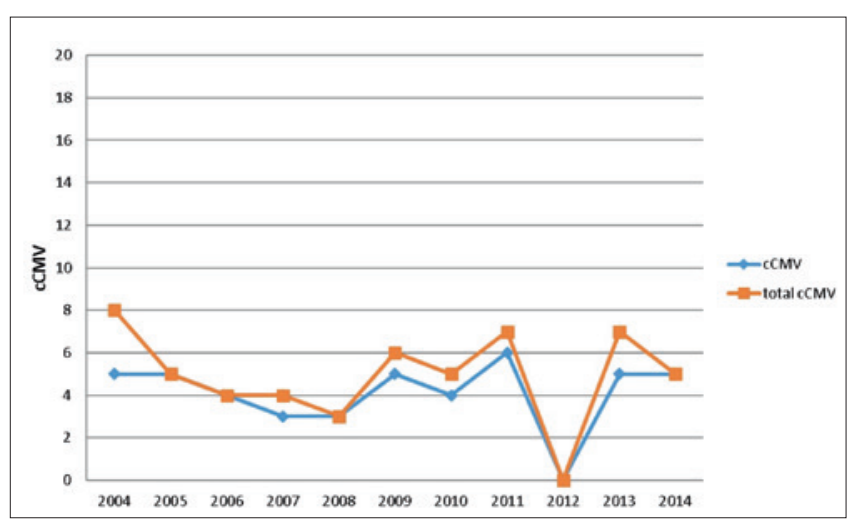

Fig. 3. The blue line shows the number of cases per year about which information on hearing loss was available, and the brown line indicates the total number of cases of cCMV diagnosed per year. In 2012 an earthquake struck the county, and only 3 of the 5 maternity wards were functioning for a 4-5 month period.
Table II. Number of children presenting with hearing loss.

\begin{tabular}{lcc} 
Hearing loss & cCMV & aCMV \\
Bilateral & & \\
Mild & 1 & 1 \\
Severe & 2 & 1 \\
Profound & 1 & 0 \\
Monolateral & & \\
Mild & 0 & 0 \\
Severe & 1 & 1 \\
Profound & 1 & 0 \\
Tot & $\mathbf{6 ( 1 3 \% )}$ & 3 \\
\hline
\end{tabular}

In particular, during the first years of the study period, clinical suspicion of infection mainly led to the urine CMV test. Near the end of the study period, CMV screening was increasingly addressed to asymptomatic high-risk infants in order to improve early diagnosis and secondary prevention strategies.

Large prospective studies reported a prevalence of 0.4$0.53 \%$ of $\mathrm{cCMV}(14)$, a recent systematic review indicates a median prevalence of $0.58 \%{ }^{3}$. In our sample, the prevalence of cCMV among tested children has showed fluctuations ranging from $1.6 \%$ to $10 \%$ that can be ascribed to the different sample size, the retrospective nature of the study and the type of population (clinical suspicion of congenital infection and/or high risk infants).

Interestingly, despite the increasing number of infants tested during the study period, the percentage of cCMV decreased, reaching the lowest percentage in the year with the larger number of infants tested. The greater and less 
selected the tested population, the lower the prevalence of cCMV. In this regard, a recent review examining the disease burden in Europe suggested that more epidemiological knowledge of cCMV infection ${ }^{18}$ is needed to assess its actual prevalence. Epidemiological patterns over the years show fluctuations in viral congenital infection rates and differences in prevalence registered in industrialised and non-industrialised countries, suggesting that other factors, e.g. environmental or genetic, may be involved ${ }^{19}$. Retrospective studies on populations of deaf children report a percentage of $2-18 \%$ of hearing loss cases due to cCMV, but its real prevalence is not yet precisely known, as in most countries CMV infection is not screened during pregnancy or in newborn ${ }^{142021}$. In the last 20 years, it has also been assumed that asymptomatic cCMV can be a significant cause of hearing loss. The question is still complex as childhood hearing impairment is the result of the intersection of different factors such as genetic predisposition and intrauterine, as well as perinatal and postnatal factors.

In our sample, the prevalence of hearing loss in cCMV infection was $13.3 \%$, similar to that reported in a systematic review by Goderis ${ }^{3}$, indicating an overall $12.6 \%$ prevalence of cCMV with a $76 \%$ rate of severe to profound hearing loss. In detail, the proportion of symptomatic cCMV with hearing loss is higher after the year of implementation of prevention programs such as the newborn hearing screening and Italian paediatric guidelines ${ }^{16} 17$.

It is well established that delayed identification of hearing loss can compromise a child's language acquisition and cognitive and psychosocial skills, but it is important to highlight that since hearing impairment may present after the neonatal period, a screening program at birth would fail to identify children with cCMV who will develop hearing loss later. In fact, in a recent study it was demonstrated that a cCMV screening program within the context of newborn hearing screening protocol can identify the majority of infants with CMV-related sensorineural hearing loss at birth, while missing cases at risk for late onset hearing impairment ${ }^{5}$.

Currently there is a growing interest in the feasibility and benefit of linking screening for cCMV infection and neonatal audiological screening as many consider implementing a universal cCMV screening program to be an onerous solution ${ }^{22-24}$.

The only way to measure the real impact of cCMV related hearing impairment on the infant population, especially in the late onset form, would be to exclude with all certainty other concomitant causes of hearing loss: for example, new hereditary sensorineural hearing loss are revealed every day, and it cannot be excluded that some genetic factors could facilitate virus-related damage to the inner ear.
None of the children of our study reported significant worsening of hearing loss after the neonatal period, and in particular none of the $51 \%$ with 8 years follow-up; this data confirms that delayed onset of hearing loss, even though possible, is not a predictable condition in cCMV infection. A recent study on a murine CMV-induced hearing loss model, which demonstrated that host derived inflammatory responses and not direct virus-mediated cytopathology may be responsible for hearing impairment ${ }^{25}$, can explain the waywardness of cochlea-vestibular damage.

Long-term audiological follow-up for at least 6 years is recommended, and audiological surveillance of children together with monitoring of communicative skills are essential to minimise adverse consequences of hearing loss, and require a multidisciplinary approach to the problem.

This retrospective study has some limitations. Firstly, our sample accounts for only $2.6 \%$ of the infants born during the study period, and no information is added with respect to the prevalence of cCMV infection in the general population. Secondly, we cannot exclude that a few children who were scored normally hearing by paediatricians might suffer from slight/mild hearing loss or a monolateral loss whose signs were not reported by parents. Finally, due to organisational issues, we were unable to detect CMV DNA by PCR on neonatal dried blood spots when the urine sample was collected later than 14 days of life. Taking into account all these limitations, we agree on the necessity of more epidemiological European studies, mainly because the impact of environmental and genetic factors is still not fully understood. The synergy between universal newborn hearing screening program and cCMV testing for asymptomatic infants who failed the TEOAE test allows early diagnosis of congenital CMV infection and the beginning of follow-up strategies and secondary prevention programs.

\section{Conclusions}

Congenital CMV infection is still one of the main causes of hearing loss in the paediatric population and a large debate on the introduction of a universal newborn screening for cCMV infection is ongoing. The question is complex, as childhood hearing loss is the result of different factors such as genetic predisposition as well as perinatal and postnatal factors. A targeted CMV approach testing newborns who fail hearing screening is useful to identify most of children with CMV-related sensorineural hearing loss as the impact of environmental and genetic factors on viral infection rates is still not fully understood. 


\section{Conflict of interest statement}

None declared.

\section{References}

1 Grosse SD, Ross DS, Dollard SC. Congenital cytomegalovirus (CMV) infection as a cause of permanent bilateral hearing loss: a quantitative assessment. J Clin Virol 2008;41:57-62.

2 Dollard SC, Grosse SD, Ross DS. New estimates of the prevalence of neurological and sensory sequelae and mortality associated with congenital cytomegalovirus infection. Rev Med Virol 2007;17:355-63.

3 Goderis J, De Leenheer E, Smets K, et al. Hearing loss and congenital CMV infection: a systematic review. Pediatrics 2014;134:972-82.

4 Das VK. Aetiology of bilateral sensorineural hearing impairment in children: a 10 year study. Arch Dis Child 1996;74:8-12.

5 Fowler KB, McCollister FP, Sabo DL, et al. A targeted approach for congenital cytomegalovirus screening within newborn hearing screening. Pediatrics 2017;139:e20162128.

6 Kenneson A, Cannon MJ. Review and meta-analysis of the epidemiology of congenital cytomegalovirus (CMV) infection. Rev Med Virol 2007;17:253-76.

7 Medearis DN. Viral infections during pregnancy and abnormal humana development. Am J Obstet Gynecol 1964;90:1140-8.

8 Britt WJ. Cytomegalovirus. In: Remington JS, Klein JO, Wilson CB, et al., editors. Infectious diseases of the fetus and newborn infant. Philadelphia: Elsevier Saunders; 2011. pp. 706-55.

9 Teissier N, Bernard S, Quesnel S, et al. Audiovestibular consequences of congenital cytomegalovirus infection. Eur Ann Otorhinolaryngol Head Neck Dis 2016;133:413-8.

10 Zagólski O. Vestibular-evoked myogenic potentials and caloric stimulation in infants with congenital cytomegalovirus infection. $\mathbf{J}$ Laryngol Otol 2008;122:574-9.

11 Fowler KB, Boppana SB. Congenital cytomegalovirus (CMV) infection and hearing deficit. J Clin Virol 2006;35:226-31.

12 Rosenthal LS, Fowler KB, Boppana SB, et al. Cytomegalovirus shedding and delayed sensorineural hearing loss: results from longitudinal follow-up of children with congenital infection. Pediatr Infect Dis J 2009;28:515-20.
13 Cannon MJ, Griffiths PD, Aston V, et al. Universal newborn screening for congenital CMV infection: what is the evidence of potential benefit? Rev Med Virol 2014 ;24:291-307.

14 Foulon I, Naessens A, Foulon W, et al. A 10 year prospective study of sensorineural hearing loss in infants with congenital cytomegalovirus infection. J Pediatr 2008;153:84-8.

15 Kadambari S, William EJ, Luck S, et al. Evidence based management guidelines for the detection and treatment of congenital CMV. Early Hum Dev 2011;87:723-8.

16 GPG/2011/498. Screening uditivo neonatale e percorso clinico ed organizzativo per i bambini affetti da ipoacusia in Emilia-Romagna. Approvazione linee guida per le aziende sanitarie. 23 maggio 2011, N. 694, Boll. Uff. RER, 6 luglio 2011,18-49.

17 Linee guida SIN. www.simast.it/linee-guida/percorsi-diagnosticoassist/citomegalovirus.

18 Ludwig A, Hengel H. Epidemiological impact and disease burden of congenital cytomegalovirus infection in Europe. Eur Surveill 2009; 14:26-32.

19 Marsico C, Kimberlin DW. Congenital cytomegalovirus infection: advances and challenges in diagnosis, prevention and treatment. Ital J Pediatr 2017;4:38.

20 Sculerati N. Analysis of a cohort of children with sensory hearing loss using the SCALE systematic nomenclature. Laryngoscope 2000;110:787-98.

21 Ohlms LA, Chen AY, Stewart MG, et al. Establishing the etiology of childhood hearing loss. Otolaryngol Head Neck Surg 1999; 120:159-63.

22 Gantt S, Dionne F, Kozak FK, et al. Cost-effectiveness of universal and targeted newborn screening for congenital cytomegalovirus infection. JAMA Pediatr 2016;170:1173-80.

23 Williams EJ, Kadambari S, Berrington JE, et al. Feasibility and acceptability of targeted screening for congenital CMV-related hearing loss. Arch Dis Fetal Neonatal Ed 2014;99:F230-F6.

24 Forli F, Giuntini G, Bruschini L, et al. Aetiologic diagnosis of hearing loss in children identified through newborn hearing screening testing. Acta Otorhinolaryngol Ital 2016;36:29-37.

25 Bradford RD, Yoo YG, Golemac M, et al. Murine CMV-induced hearing loss is associated with inner ear inflammation and loss of spiral ganglia neurons. Plos Pathol 2015;11:e1004774.

Received: November 21, 2017 - Accepted: February 18, 2018

How to cite this article: Palma S, Roversi MF, Bettini M, et al. Hearing loss in children with congenital cytomegalovirus infection: an 11-year retrospective study based on laboratory database of a tertiary paediatric hospital. Acta Otorhinolaryngol Ital 2019;39:4045. https://doi.org/10.14639/0392-100X-2020

Address for correspondence: Silvia Palma, Audiology, Primary Care Unit Modena, University Hospital, Modena, via del Pozzo 71, 41100 Modena, Italy. Tel. +39059 4223901. E-mail: silviapalma@inwind.it 